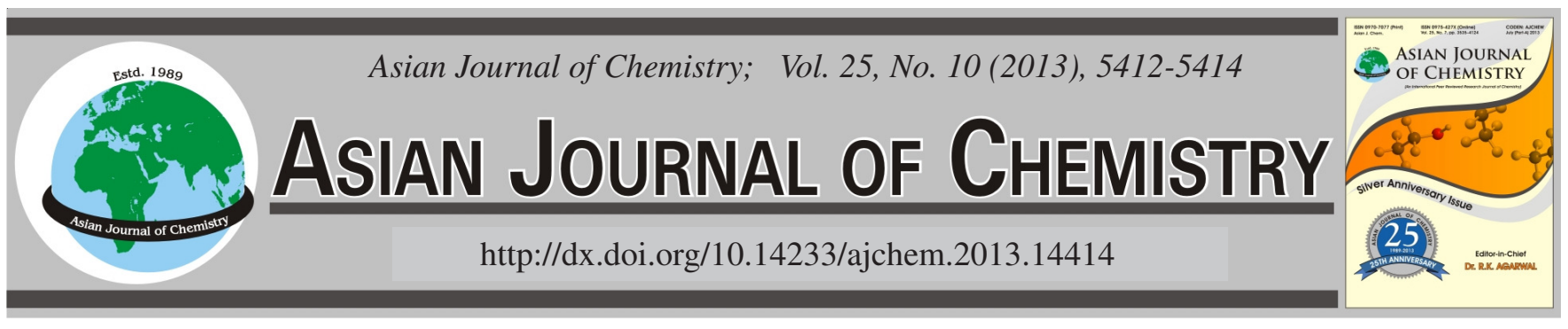

\title{
Synthesis and Bioassay of Novel Phenylhydrazine and 2,4-Dinitrophenylhydrazine Substituted Carbazoles
}

Almas Hamid ${ }^{1}$, Zubi SadiQ ${ }^{2, *}$, GhaZala Yaqub ${ }^{1, *}$, Nikhat Khan $^{1}$, Saira Iqbal ${ }^{1}$, Kashaf Iqbal ${ }^{1}$, Zainab Ijaz ${ }^{1}$ and Anum Bajwa ${ }^{1}$

${ }^{1}$ Department of Environmental Sciences, Kinnaird College for Women, Lahore-54000, Pakistan

${ }^{2}$ Department of Chemistry (Girls), College of Science, King Faisal University, Al-Ahsa-31982, Saudi Arabia

*Corresponding authors: Tel: +966 581292480; +92 331 4063466; E-mail: zubi_sadiq@ hotmail.com; ghazala_yaqub@yahoo.com

(Received: 8 August 2012;

Accepted: 8 April 2013)

AJC-13218

\begin{abstract}
The efficient and rapid synthesis of phenylhydrazine and 2,4-dinitrophenylhydrazine substituted carbazole derivatives is reported using both strategies; conventional and microwave. Both newly prepared compounds shares the same acidic media. Microwave irradiations demonstrated much suitable results with respect to every aspect. Antibacterial and antifungal potential of both compounds were evaluated in terms of minimum inhibitory concentration against Escherichia coli, Staphylococcus aureus, Pasteurella multocida, Bacillus subtilis, Aspergillus flavus, Aspergillus niger, Alternaria solani and Rhizoctonia solani.
\end{abstract}

Key Words: 1,2,3,4-Tetrahydrocarbazole derivatives, Carbazole synthesis, Microwave-assisted synthesis, Biological assay.

\section{INTRODUCTION}

Carbazole chemistry is widely studied from many decades due to its stimulating structural features and broad spectrum pharmaceutical profile ${ }^{1}$. Besides their promising antimicrobial activities $^{2}$, this nucleus also exhibited strong anticancer, anti $\mathrm{HIV}^{3}$ and antineoplastic activity. To date this heterocyclic compound has been valiantly explored by many researchers resultantly attained a stable position in medicinal field. Efficient synthetic strategies that introduced structurally modified derivatives with various applications in different era of life are well reported since its first isolation ${ }^{4}$.

This study prompted us to synthesize some new, highly effective analogues of this unique molecule that play its role as effectual antibiotics. Many traditional synthetic lines are needed to improve due to ever increasing health issues and environment pollution. That's why many of its derivatives have been successfully synthesized by microwave assisted preparation $^{5}$. Herein we also presented microwave approach to establish environment friendly synthetic method.

\section{EXPERIMENTAL}

All the chemical reagents and solvents were of analytical grade. Boiling points of both the synthesized compounds were taken by open capillary method and are incorrect. Analytical TLC having silica gel pre-coated on Al sheets (Merk $60 \mathrm{~F}_{254}$, $0.2 \mathrm{~mm}$ thick) were used. Spots were visualized under UV light at 254/365 nm (CAMAG scientific Inc). KBr disks were used to record IR spectra on Midac Corporation FTIR spectrophotometer. ${ }^{1} \mathrm{H}$ and ${ }^{13} \mathrm{C}$ NMR spectral data were recorded on Bruker AXS $300 \mathrm{MHz}$ spectrometer in DMSO- $d_{6}$ using TMS as an internal standard. U-2800 Hitachi, UV-visible spectrophotometer in $\mathrm{MeOH}$ were used to determine UV spectra. Mass spectra (MS) were recorded on a finnigan/MAT95 spectrometer at an ionizing voltage of $70 \mathrm{eV}$.

Synthesis of (Z)-1-(1-(6,7,8,9-tetrahydro-1,3-dinitro-5Hcarbazol-8-yl)ethylidene)-2-phenylhydrazine (2)

Conventional way: $0.606 \mathrm{~g}(0.002 \mathrm{~mol})$ compound 1 was dissolved in $10 \mathrm{~mL}$ glacial acetic acid. The reddish brown colouration within flask start to attain orange tint after the addition of $0.216 \mathrm{~g}(0.002 \mathrm{~mol})$ phenylhydrazine in small intervals. It was refluxed for $2.45 \mathrm{~h}$ as reaction progress was checked by TLC in $2 \% \mathrm{CH}_{3} \mathrm{OH}$ and $\mathrm{CH}_{2} \mathrm{Cl}_{2}$ solvent system. The reaction mixture was poured in crushed ice. Resultant filterate was concentrated on rotary evaporator to give $\mathbf{2}$ (Scheme-I).

Microwave approach: $0.303 \mathrm{~g}(0.001 \mathrm{~mol})$ of compound $1,0.108 \mathrm{~g}(0.001 \mathrm{~mol})$ of phenylhydrazine and $0.5 \mathrm{~mL}$ glacial acetic acid was well mixed in reaction pot. It was then placed in a domestic microwave oven at 100 power level for $30 \mathrm{~s}$. The reaction mixture was monitored by TLC. 1 min were found enough for completion of reaction. Ice cubes were then added to cool the reaction mixture. After precipitation, it was filtered out as product 2 .

UV $\lambda_{\max }(\mathrm{MeOH}): 267,281,344,385 \mathrm{~nm}$. IR (KBr, $\nu_{\max }$, $\left.\mathrm{cm}^{-1}\right): 1420\left(\mathrm{NO}_{2}\right), 1629(\mathrm{C}=\mathrm{N}), 3342(\mathrm{NH}), 3147$ (aromatic 


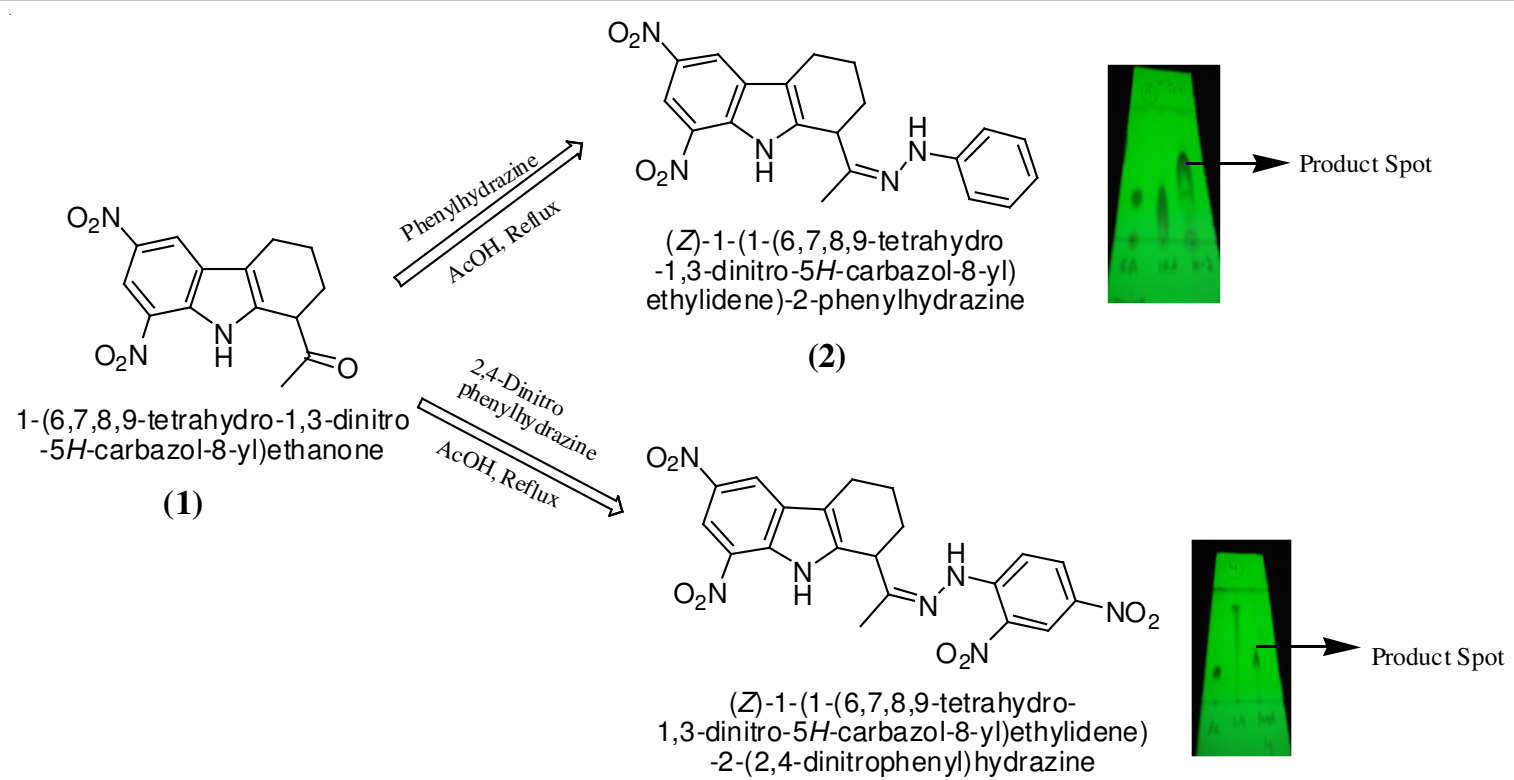

(3)

Scheme-I: Synthesis of compound $\mathbf{2}$ and $\mathbf{3}$

ring), $3449(\mathrm{NH}) .{ }^{1} \mathrm{H}$ NMR (DMSO) $\delta: 7.42(\mathrm{~m}, 5 \mathrm{H}$, aryl-H), $7.11(\mathrm{~s}, 1 \mathrm{H}, \mathrm{NH}), 2.82\left(\mathrm{~s}, 3 \mathrm{H}, \mathrm{CH}_{3}\right), 2.85(\mathrm{t}, 1 \mathrm{H}), 1.7-1.9(\mathrm{~m}$, $2 \mathrm{H}, 2 \mathrm{CH}_{2}$ cyclo), 2.19 (t, 2H), 7.40 (s. 1H, Ar-H), 9.15 (s. 1H, Ar-H), 10.2 (s, 1H, NH). ${ }^{13} \mathrm{C}$ NMR (DMSO) $\delta: 155.2,145.1$, $143.1,132.4,131.3,130.0,129.2,128.5,127.1,121.4,117.2$, $116.9,116.1,109.3,108.3,30.2,25.5,25.3,22.1,17.6 . \mathrm{MS}$ $\left(\mathrm{ES}^{+}\right): 393\left(\mathrm{MH}^{+}\right)$.

Synthesis of (Z)-1-(1-(6,7,8,9-tetrahydro-1,3-dinitro-5 $\mathrm{H}$ carbazol-8-yl)ethylidene)-2-(2,4-dinitrophenyl)hydrazine (3)

Conventional way: $0.001 \mathrm{~mol}(0.303 \mathrm{~g})$ of compound $\mathbf{1}$ was refluxed for $2.5 \mathrm{~h}$ in the presence of acidic media with $0.198 \mathrm{~g}$ (0.001 mol) 2,4-dinitrophenylhydrazine. The reaction mixture exhibited reddish orange colour after the addition of whole reagent. Eluent for this reaction was $1 \%$ EtOAc and $\mathrm{CH}_{2} \mathrm{Cl}_{2}$ while spots were visualized under UV-light that confirmed the product formation. Work up conditions was same as adopted for $\mathbf{2}$ that produced $\mathbf{3}$ (Scheme-I).

Microwave approach: $0.198 \mathrm{~g}(1 \mathrm{mmol})$ of 2,4-dinitrophenylhydrazine was well mixed with equimolar mixture of 6,8-dinitro-1-acetyl-1,2,3,4-tetrahydro-9H-carbazole (1) and glacial acetic acid. The reaction mixture was irradiated with microwaves with the interval of $10 \mathrm{~s}$. The reaction progress was monitored by TLC and it confirmed the product formation in $1 \mathrm{~min}$. The contents of reaction mixture were poured into crushed ice. After $15 \mathrm{~min}$, it was filtered off. The compound $\mathbf{3}$ was obtained in $91 \%$ yield.

UV $\lambda_{\max }(\mathrm{MeOH}): 269,293,345,389 \mathrm{~nm}$. IR (KBr, $v_{\max }$, $\left.\mathrm{cm}^{-1}\right): 1420\left(\mathrm{NO}_{2}\right), 1629(\mathrm{C}=\mathrm{N}), 3342(\mathrm{NH}), 3147$ (aromatic ring), $3449(\mathrm{NH}) .{ }^{1} \mathrm{H}$ NMR (DMSO) $\delta: 7.29(\mathrm{~d}, J=7.3 \mathrm{~Hz}$, 1H, Ar-H), 7.54 (d, J=7.4 Hz, 1H, Ar-H), 7.33 (s, 1H, Ar-H) remaining signals were in co-ordinance with compound $2 .{ }^{13} \mathrm{C}$ NMR (DMSO) $\delta: 156.4,155.2,142.7,138.8,136.8,135.4$, 132.4, 131.5, 130.0, 128.1, 121.5, 119.2, 117.9, 109.7, 108.2, 30.2, 25.8, 25.3, 22.6, 17.8. MS (ES $)^{+}: 483\left(\mathrm{MH}^{+}\right)$.

The physical characteristics of compounds $\mathbf{2}$ and $\mathbf{3}$ are given inTable-1.

Pharmacological evaluation: Antimicrobial assay: Both the newly synthesized compounds ( 2 and $\mathbf{3}$ ) were evaluated for their in vitro antibacterial activity against Escherichia coli, Staphylococcus aureus, Pasteurella multocida and Bacillus subtilis and antifungal screening against clinically important strains of Aspergillus flavus, Aspergillus niger, Alternaria solani and Rhizoctonia solani by agar well diffusion method. DMSO was used to dissolve test compounds. Results were recorded as minimal inhibitory concentration (MIC) values and presented in Table-2. MIC of compounds was variable according to the antimicrobial strains.

\section{RESULTS AND DISCUSSION}

In the present study, we explore two novel derivatives of carbazole having additional phenyl ring in its structure. Treatment of compound 1 with phenylhydrazine and 2,4dinitrophenylhydrazine in suitable acidic media successfully furnished desire compounds $\mathbf{2}$ and $\mathbf{3}$. Heating the reaction contents up to reflux point for a particular time in case of traditional approach is the reaction requirement that was fulfilled. While reaction methodology in microwave utilize molecular excitation due to electromagnetic radiation. Enormous accelerations at ambient pressure is a dragging force that reduces time requirement from hours to seconds. Conventional conditions were compared with microwaves that ultimately offer a

TABLE-1

REACTION SUMMARY AND PHYSICAL CHARACTERISTICS OF COMPOUNDS 2 AND 3

\begin{tabular}{|c|c|c|c|c|c|c|c|}
\hline Compounds & b.p. $\left({ }^{\circ} \mathrm{C}\right)$ & & & m.f. & m.w. $(\mathrm{g} / \mathrm{mol})$ & Reflux time (h) & $\mu \mathrm{w}$ Irradiation (s) \\
\hline 2 & 162 & $73 *$ & 90 & $\mathrm{C}_{20} \mathrm{H}_{19} \mathrm{~N}_{5} \mathrm{O}_{4}$ & 393 & 2.45 & 60 \\
\hline 3 & 198 & $60 *$ & 91 & $\mathrm{C}_{20} \mathrm{H}_{17} \mathrm{~N}_{7} \mathrm{O}_{8}$ & 483 & 2.5 & 60 \\
\hline
\end{tabular}

*Less yield is for conventional process. 


\begin{tabular}{ccccc}
\hline \multicolumn{5}{c}{ TABLE-2 } \\
ANTIMICROBIAL ACTIVITY DATA OF 2 AND 3 \\
\hline \multirow{3}{*}{ Compounds } & \multicolumn{4}{c}{ MIC (mg/mL) } \\
\cline { 2 - 5 } & \multicolumn{4}{c}{ Bacterial strains } \\
\cline { 2 - 5 } & Escherichia coli & Staphylococcus aureus & Pasteurella multocida & Bacillus subtilis \\
\hline $\mathbf{2}$ & 5.0 & 0.02 & $1.8 \times 10^{-3}$ & $1.8 \times 10^{-3}$ \\
$\mathbf{3}$ & 1.2 & 0.15 & $5.3 \times 10^{-3}$ & Rhizoctonia solani \\
\hline & \multicolumn{5}{c}{ Fungal strains } \\
\hline $\mathbf{2}$ & Aspergillus flavus & Aspergillus niger & Alternaria solani & 3.30 \\
\hline
\end{tabular}

favorable approach to adopt green chemistry. The structural elucidation of newly synthesized analogues were corroborated by UV, FTIR, ${ }^{1} \mathrm{H}$ NMR, ${ }^{13} \mathrm{C}$ NMR and mass spectrometry. The antimicrobial screening studies revealed that both the compounds behaves differently against different pathogenic strains. Compound 2 exhibited excellent antibacterial behaviour against Pasteurella multocida and Bacillus subtilis while moderately effective is observed in contrast to fungal strains. In case of compound 3, Pasteurella multocida is the bacterial strain against which this potent compound shows fine activity even at $4.5 \times 10^{-3} \mathrm{mg} / \mathrm{mL}$. The antifungal activity of this compound is considered from good to moderate (Table-2).

\section{Conclusion}

To introduce novel derivatives via efficient synthetic routes to medicinally important compounds is the need of time. As a contribution to this, we effectively synthesized two compelling biologically active compounds $\mathbf{2}$ and $\mathbf{3}$ via traditional and microwaves heating. Results of antimicrobial screening of the tested compounds proved the potential of prepared compounds to stand among future antibacterial and antifungal agents.

\section{ACKNOWLEDGEMENTS}

The authors are highly thankful to Higher Education Commission Pakistan for financial assistance under program of IPFP's and Dr. Erum Akbar Hussain for her valuable guidance during this research.

\section{REFERENCES}

1. (a) N. Haider, J. Heterocycl. Chem., 39, 511 (2002); (b) G. Yaqub, A. Hannan, E. Akbar, M. Usman, A. Hamid, Z. Sadiq and M. Iqbal, J. Chem., Article ID 818739 (2013).

2. A.D. Isravel and J.R.P. Karnam, Acta Pharm., 53, 287 (2003).

3. K. Hirata, C. Ito, H. Furukawa, M. Itoigawa, L.M. Cosentino and K.-H. Lee, Bioorg. Med. Chem. Lett., 9, 119 (1999).

4. G. Yaqub, E.A. Hussain, M.A. Rehman and B. Mateen, Asian J. Chem., 21, 2485 (2009).

5. W.J. Lao, Y.H. Zhang, Y.Q. Liu, Q.J. Wu, Z.X. Huang and Q.Y. Ou, Chin. Chem. Lett., 12, 321 (2001). 